\title{
The development of the noncommunicable diseases emergency health kit
}

Slim Slama ${ }^{1}$, Jonathan Lee ${ }^{2}$, Mauricio Aragno ${ }^{1}$, Sophie Laroche ${ }^{3}$ and Hans Hogerzeil 4

${ }^{1}$ World Health Organization Regional Office for the Eastern Mediterranean, Cairo, Egypt. (Correspondence to: Slim Slama: slamas@who.int) ${ }^{2}$ New York Presbyterian Hospital, Columbia University, New York, United States of America. ${ }^{3}$ World Health Organization, Geneva, Switzerland. ${ }^{4}$ University of Groningen, Groningen, the Netherlands.

\begin{abstract}
The noncommunicable diseases (NCDs) emergency health kit was developed in response to the growing prevalence of NCDs in low and middle-income countries. Under conditions of conflict or following natural disasters, regular treatment of this category of diseases is often disrupted and rarely prioritized. This leads to greater morbidity and mortality both in the short and long term. The Eastern Mediterranean Region (EMR) has both a high incidence of NCDs and currently is the site of several major conflicts and hosts most of the world's refugees. Therefore, the WHO Regional Office for the Eastern Mediterranean initiated the development of the NCD emergency health kit to provide a structured set of medications, equipment and renewables to supply the needs of a population of 10000 people over a period of 3 months following disruption of normal medical services. This report discusses the rationale and anticipated use of the NCD emergency health kit followed by the selection criteria, structure, content and quantification process of the kit. Finally, the next steps are examined, including the procurement, logistics and monitoring and evaluation process of the kit.
\end{abstract}

Keywords: Noncommunicable diseases; humanitarian emergency; emergency kits; conflict; disaster

Citation: Slama S, Lee J, Aragno M, Laroche S, Hogerzeil, H. The development of the noncommunicable diseases emergency health kit. East Mediterr Health J. 2018;24(1):92-98. https://doi.org/10.26719/2018.24.1.92

Received: 17/12/17; accepted 18/01/18

Copyright (C) World Health Organization (WHO) 2018. Some rights reserved. This work is available under the CC BY-NC-SA 3.o IGO license (https:// creativecommons.org/licenses/by-nc-sa/3.o/igo).

\section{Introduction}

Since 1984, the WHO emergency health kit, which evolved to become the Interagency Emergency Health Kit (IEHK), has provided relief for the health needs of populations in crisis (1). The intention of the kit was to temporarily provide the essential medications and supplies for a population of 10000 . This would cover a 3-month period when health infrastructure has been disrupted by conflict, or in the immediate aftermath of a natural disaster. Through its evolution, the emergency health kit has gone through several revisions and modular additions including a module for malaria treatment and a module for HIV treatment (2). Subsequent kits have been developed to serve other health needs of populations, such as the surgical kit (3) and the reproductive health kit (4).

Despite their utility, these kits have yet to address noncommunicable diseases (NCDs) in accordance with the shifting burden of diseases worldwide (5). The IEHK includes a small amount of NCD medication. However, it does not have the capacity to provide either the kind of medications needed or a sufficient quantity to treat populations that have high prevalence of NCDs, like those seen in certain low and middle-income countries (LMIC).

Noncommunicable diseases account for $70 \%$ of all deaths globally and of those deaths over $40 \%$ are premature, occurring before the age of 70 . Despite the myth that NCDs are diseases of developed nations,
$82 \%$ of those premature deaths occur in LMICs (6). In addition, given the scale and impact across the globe, the economic implications are significant. In 2011, the United Nations General Assembly called a high-level meeting to put NCDs on the agenda. The following year, the World Health Organization (WHO) produced the 'Global Action Plan for the Prevention and Control of Noncommunicable Diseases' as a framework for tackling this burden. Among its recommendations is Article 49, which states the deployment of "an interagency emergency health kit for treatment of noncommunicable diseases in humanitarian disasters and emergencies" (7).

The WHO Regional Office for the Eastern Mediterranean (WHO/EMRO) has taken the initiative to create an NCD emergency health kit to complement the IEHK for several reasons. First, the Eastern Mediterranean Region (EMR) has one of the highest prevalence of NCDs worldwide. With an adult hypertension prevalence ranging from 20 to $30 \%$ (8) and diabetes prevalence of $14 \%$ (9), NCDs are one of the greatest health burdens in the Region. Second, the EMR hosts the majority of the world's current refugees and internally displaced persons (IDPs) $(10,11)$. With numerous countries in emergencies and many others hosting refugees, the Region would benefit most from an NCD emergency health kit.

The purpose of this report is to present and share the development process of the NCD emergency health kit. The report is divided into three sections: 1 ) it describes the rationale, purpose and anticipated use of the NCD kit; 2) it presents the structure, selection criteria, contents and 
quantification process of the kit; and 3) it discusses the way forward, including the procurement, logistics, and monitoring and evaluation process of the kit at selected pilot sites.

\section{Rationale and purpose of the NCD kit}

In accordance with the minimum standards of the Sphere guidelines, the kit is built around several priority actions. First, it aims to provide the ongoing medication requirements of people who are already on treatment, in order to reduce the risk of acute exacerbations and complications that lead to morbidity and mortality. As a caveat, the kit does not support the initiation of medications for those that are newly diagnosed as outlined in the Sphere guidance notes (12). Second, the kit is meant for the primary health care (PHC) level. However, in an emergency the capacity to provide various levels of care is heavily dependent upon human resources, and often that capacity to deliver NCD care is limited among humanitarian providers. Anticipating these difficulties, the NCD emergency health kit serves a variety of health care settings. The kit can be deployed in various locations such a mobile health clinic, primary health centre, field hospital, or if necessary in a tertiary hospital.

\section{Structure of the kit}

The NCD emergency health kit consists of 5 submodules (Table 1). Module 1A (medicines), contains mostly oral tablets alongside two different inhalers. Medicines requiring cold chain, namely subcutaneous insulin, were placed in a separate module (1B), to allow for their proper handling. The third module $(\mathrm{IC})$, contains medical renewables, such as syringes, lancets and blood and urine strips. The final two modules (1D and $1 E)$ contain equipment renewables and the equipment itself, selected for basic diagnostic ability.

The modularity of the kit was designed to offer maximum flexibility, based on country needs and capacity. For instance, the exclusion of insulin from the medicines submodule into its own cold chain submodule was a decision based on logistics and resource uncertainty in the field. Emergency situations are unpredictable and some situations may not allow for proper refrigeration facilities, which in this case, the insulin module $1 B$ may be removed from the order. The same idea applies for the equipment renewables submodule, since it is assumed that the medical equipment module will be ordered only once, providing the ability to order separately the renewables for those equipment. The first three modules are intended to provide sufficient medications and renewables for the 3-month initial period.

This modularity allows for flexibility in the uncertain climate of emergencies. The kit does not have to be ordered as a whole, but may be ordered by submodules depending on the needs of the field. The assumption would be that after the first order of the full kit, subsequent orders may include only the medications and renewables, excluding other longer lasting or less utilized submodules.

\section{Content of the kit and selection criteria}

The selection criteria of medicines involved several steps. First, it was important that all medicines are congruent with the WHO Essential Medicines List (13), guidelines from the 'Package of Essential Noncommunicable (PEN) Disease Interventions for Primary Health Care in LowResource Settings' (14), and the Mental Health Gap Action Programme (mhGAP) (15). This allows for a standardized evidence-based kit with known reliability. Following this process was a review of previous emergency health kits for the treatment of NCDs such as the Balkan kit, the NCD kit utilized in Ukraine, and the mini emergency health kit utilized in Pakistan. Finally, soliciting comments from the field in emergency countries was important in understanding the experience on the ground with regards to NCDs. An extensive literature review and a regional situational analysis on the provision of NCD care to Syrian refugees informed the prioritization of diseases to be covered (16).

Following the desk review process on 20 July 2016, a multi-agency consultation meeting involving field and technical experts of various disciplines was hosted by WHO/EMRO in Cairo, Egypt. A discussion weighing existing literature, population needs, and practical field experience was carried out. This process resulted in the finalization of the list of medications and equipment to be included in the kit. Also discussed in the meeting were the next steps, including the process of procurement, field testing, logistics, and monitoring and evaluation (M\&E).

This emergency kit is designed to treat the major NCDs, namely hypertension and cardiac conditions,

\begin{tabular}{|c|c|c|c|}
\hline Basic module & $\begin{array}{c}\text { Weight } \\
\text { (kg) }\end{array}$ & $\begin{array}{l}\text { Size } \\
(\mathrm{cm})\end{array}$ & $\begin{array}{c}\text { Volume } \\
\left(\mathrm{m}^{3}\right)\end{array}$ \\
\hline Module (1A): Medicines only, without cold chain insulin & 235 & $120 \times 80 \times 120$ & 1.920 \\
\hline Module (1B): Medicines cold (insulin) & 10 & $120 \times 80 \times 80$ & 0.768 \\
\hline Module ( $1 \mathrm{C})$ : Medical renewables & 21.8 & $60 \times 40 \times 42$ & 0.1008 \\
\hline Module (1D): Equipment supplies & 141 & $120 \times 80 \times 87$ & 0.8352 \\
\hline Module (1E): Equipment & 8.6 & $60 \times 40 \times 27$ & 0.0648 \\
\hline Total & 416.4 & & 3.689 \\
\hline
\end{tabular}


diabetes, chronic respiratory diseases, and a selected set of mental health and neurological diseases (Figure 1). Certain disorders such as cancers, autoimmune disorders and end-stage renal diseases require complex diagnostic infrastructures, expensive specialized care, and have treatment regimens with narrow therapeutic windows. These could result in adverse side effects not amenable to disrupted health systems. Excluding these conditions, the kit covers the essential NCD health care needs of a population with a focus on the primary health care level.

As a response to the demand for palliative care in emergencies, the kit's original intention was to include medications for both pain and non-pain related symptomatic relief, with guidance from WHO's technical report on the 'Selection and Use of Essential Medicines' (17). However, with consultations from experts and practitioners, the ultimate decision was made to exclude these medications. This was due to tensions related to regulatory restrictions and transportation impediments across different Member States, plus possible unintended consequences of controlled medications in a climate of uncertain security. This point illustrates the various dilemmas encountered in the design and selection of medicines included in the kit.

Reduction of overlap between the NCD kit and the IEHK was crucial to prevent redundant surplus of supplies in the field. For this reason, medications for eclampsia in pregnancy such as methyldopa, hydralazine and magnesium sulfate, were removed. Although the NCD kit serves to complement the IEHK, it was important for it to have stand-alone capacity and not be completely dependent on supplies included in other kits. Thus, the inclusion of basic equipment such as sterile gloves, stethoscopes, sphygmomanometers and thermometers was strategic.

\section{Quantification of drug requirements}

The quantification of medications was based on a combination of known data and general trends. Data from WHO's NCD country profiles in the EMR were utilized to extrapolate regional prevalence and incidence of conditions (18). Upon further evaluation was the assumption regarding coverage trends, meaning the percentage of patients who are on treatment for a certain disease. For instance, at a given prevalence of diabetes there was an assumption based on trends that about $50 \%$ of patients were on pharmacologic therapy. Further assumptions were made for patients on treatment, for which the percentage of patients on insulin therapy was about $20 \%(19)$. The same process was calculated for hypertension data (20) with trends regarding the percentage of patients who are on monotherapy versus dual-therapy regimens (8). After prevalence and coverage calculations, the number of physical tablets needed was based on the WHO essential medicines list (EML) formulary to assess dosages and frequency of consumption (13). For medical equipment, further considerations were needed. Consumables such as glucose strips and syringes were based on prevalence data as mentioned above. Other devices such as glucometers, sphygmomanometers and stethoscopes were based on the number of health care professionals at facilities as well. Spare parts and consumables attached to devices were also calculated considering the lifespan of the devices.
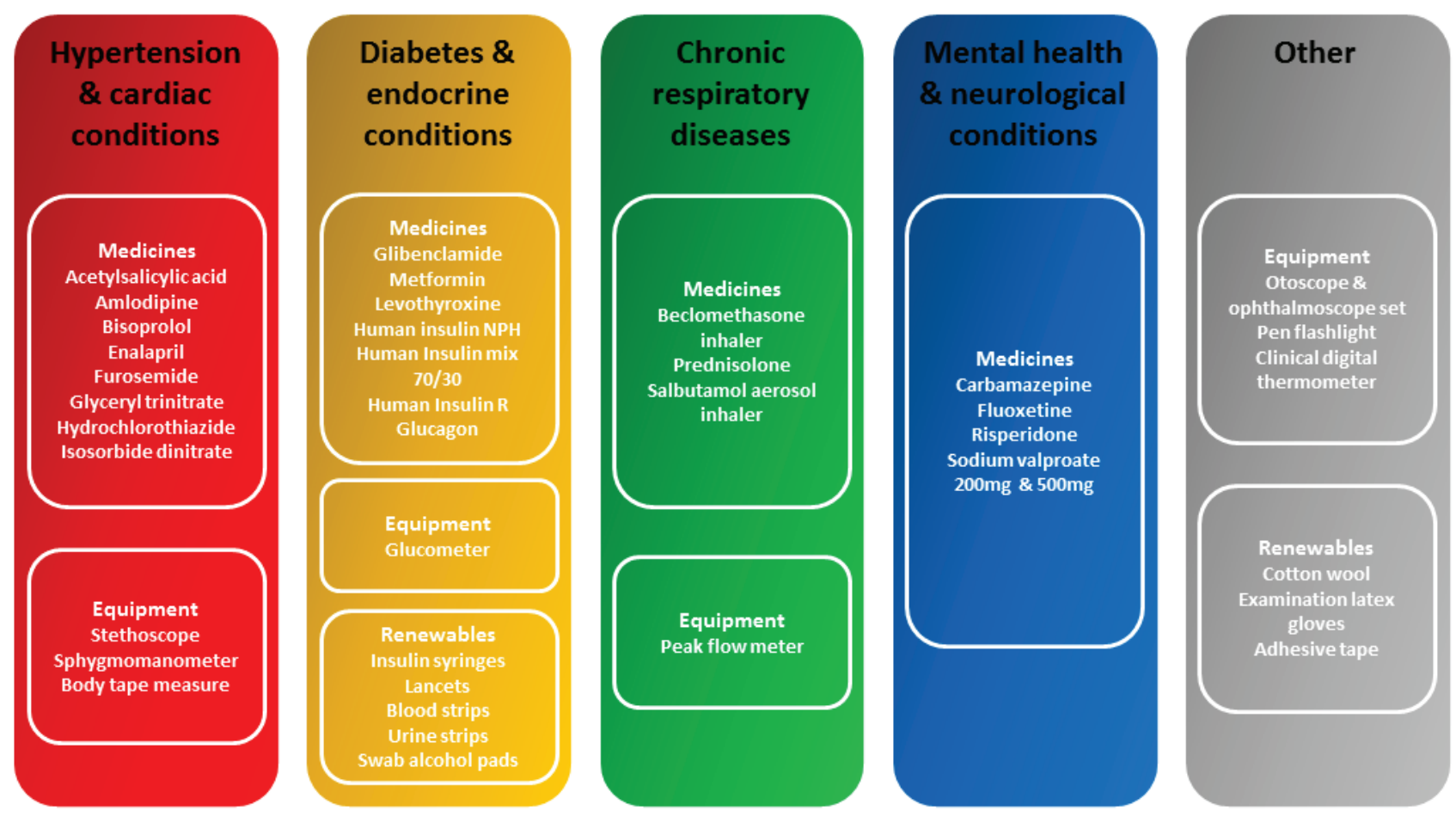


\section{Next steps}

\section{Procurement, logistics, monitoring and evaluation}

The procurement process of the NCD kit was made through international competitive bidding. Technical specifications for all items were incorporated in the call for proposals to international suppliers. The review of suppliers' proposals involved a multidisciplinary team including physicians, pharmacists and biomedical engineers. All proposed items were evaluated against the following selection: 1) quality of the drugs; 2 ) compliance with the technical specifications for medical devices; 3 ) certifications and quality/safety assurance for medical devices; 4) drug packaging (e.g. blister versus jars); 5) total price of the kit (not module based); 6) Lead-time for the supplier to deliver the first set of kits; and 7) weight and volume.

For example, the consideration of drug packaging in jars versus blister packs were discussed, since packaging may not only affect the end prescriber and user but may also alter the weight and volume of the kit, thus having an effect on the cost and transportation. Additional considerations for devices include voltage and socket congruency and language specifications for instructions depending on the receiving country. Suppliers identified manufacturers globally and obtained price estimates. As part of the quality control process, WHO ensured that suggested manufacturers were certified by regulatory authorities and/or show adherence to WHO Good Manufacturing Practices. After selecting one supplier, WHO made a visit to the site of production to check all items included in the kit. Current cost estimates for a full kit providing for 10000 people over a period of 3 months range from US\$13000 to US\$15000. According to the supplier, first production of kits took approximately 3 months to assemble. However, supplies are planned to be stocked by the supplier in order to guarantee rapid shipment within 48 hours.

\section{Piloting sites and logistics}

Following the selection of a supplier, discussions took place on where to first deploy the kits. The criteria for selecting pilot sites for NCD kit deployment was the following:

1. countries with high NCD burden/caseload based on reporting by partners and minimum catchment population of 10 ooo people

2. NCD medicines shortage/supply chain disruption

3. minimum technical capacity to deliver NCD medicines

4. cold chain structure/equipment availability

5. capacity to provide basic feedback on kit use (monitoring and evaluation activities).

Based on these criteria, a choice was made to start implementation of the kit in several sites across Iraq and the Syrian Arab Republic. The first set of kits reached the north of the Syrian Arab Republic in October 2017. In order to set the baseline for sites' selection and to start gathering information for deployment plan development, a comprehensive questionnaire has been sent to each of the selected sites. This involved finalizing the quantity of orders, producing a distribution plans for each site, and foreseeing any obstructions. The number of kits to be ordered required an estimate of the catchment area population served by each health facility. In addition, the number of kit modules orders was tailored to the size of the population and patient volume to be served. Given the nature of conflict and insecurity, an additional number of kits were ordered as a buffer stock to ensure continuity of care as unpredictable patency of humanitarian corridors could impede delivery. Movements across borders depend on the export and import country; further steps were necessary including registration of suppliers within the import country, certification of medications, and proper documentation for cross border activities.

\section{Monitoring and evaluation}

Following up on the NCD kit's usage is an integral process. By obtaining proper feedback and data, critical information will be obtained on whether the kit content and quantities served the needs of the population as originally intended. Particularly after the first launch of the kit, proper data collection and analysis will be essential to guide future revisions. This process will not only inform the production of a more cost-effective kit, but more importantly create a kit that can best serve populations in emergencies.

For that purpose, a monitoring and evaluation framework was designed that follows the journey of the kit from the supplier to end-user. Monitoring and Evaluation (M\&E) activities were divided into 3 phases: 1) a pre-deployment phase; 2) a mid-term monitoring phase; and 3) an end-term evaluation phase. Survey questionnaires were developed and connections with first-line service providers were set up to get regular feedbacks. Anticipating that insecurity would hamper the ability to perform direct visits to implementing sites, an electronic platform and mobile applications were set up to allow remote monitoring of the kit deployment and use. Consisting of a comprehensive suite of tools, the electronic platform would allow for the remote administration of surveys, export of data, and visualization of results. The M\&E timeline and type of data collected during the various implementation phases are outlined in Table 2.

\section{Discussion}

"Health system resilience can be defined as the capacity of health actors, institutions, and populations to prepare for and effectively respond to crises; maintain core functions when a crisis hits; and, informed by lessons learned during the crisis, reorganize if conditions require it" (21).

During emergencies, lives are lost primarily to the effect of the environment, communicable diseases 
Table 2 Monitoring and Evaluation timeline at pilot sites

\begin{tabular}{|c|c|c|c|}
\hline NCD kit M/E phases & $\begin{array}{c}\text { Pre-deployment phase } \\
\text { Day o }\end{array}$ & $\begin{array}{l}\text { Mid-term monitoring } \\
3 \text { months }\end{array}$ & $\begin{array}{l}\text { End-term evaluation } \\
6 \text { months }\end{array}$ \\
\hline When & Upon kit arrival and before its use & At 3 months of kit arrival & At 6 months of kit arrival \\
\hline Objective & $\begin{array}{l}\text { - To provide a starting baseline for } \\
\text { kit use } \\
\text { - To be informed about parallel } \\
\text { supplies and document storage } \\
\text { capacity and conditions } \\
\text { - To verify NCD kit has reached its } \\
\text { final destination }\end{array}$ & $\begin{array}{l}\text { - To follow up kit use in } \\
\text { particular in term of content and } \\
\text { quantification against ordered } \\
\text { numbers of complete kits/ } \\
\text { submodules }\end{array}$ & $\begin{array}{l}\text { - To review NCD kit structure, content } \\
\text { and quantities adequacy to field needs } \\
\text { against pre-existing readiness and } \\
\text { estimated needs }\end{array}$ \\
\hline $\begin{array}{l}\text { Areas covered by } \\
\text { monitoring and } \\
\text { evaluation }\end{array}$ & $\begin{array}{l}\text { - Contextual analysis (emergency, } \\
\text { service delivery readiness relevant } \\
\text { to NCD management) } \\
\text { - Baseline assessment (drugs } \\
\text { stocks, storage capacity, cold chain) } \\
\text { - Kit inspection upon reception }\end{array}$ & $\begin{array}{l}\text { - Relevance of kit content to daily } \\
\text { practice } \\
\text { - Early stock-outs or non-used } \\
\text { items }\end{array}$ & $\begin{array}{l}\text { - Relevance of kit content for the } \\
\text { management of most common NCDs } \\
\text { - Relevance of drug quantities to } \\
\text { estimated population coverage } \\
\text { - Relevance of kit modularity and drug } \\
\text { packaging } \\
\text { - Relevance of supportive documentation } \\
\text { (drug formulary, standards treatment } \\
\text { guidelines) to local practice }\end{array}$ \\
\hline Methods & E-survey & Follow up calls to piloting sites & E-survey \\
\hline $\begin{array}{l}\text { Focal points to } \\
\text { collect data }\end{array}$ & pharmacists/logisticians & $\begin{array}{l}\text { Medical officer or third party } \\
\text { in charge of the supervision of } \\
\text { primary health care facility }\end{array}$ & $\begin{array}{l}\text { Medical officer or third party in charge } \\
\text { of the supervision of primary health care } \\
\text { facility }\end{array}$ \\
\hline
\end{tabular}

and trauma. Humanitarian objectives aim to reduce as many of these excess deaths as possible. However, it is important to address not only the new diseases but also the existing health burdens prior to the emergency. Noncommunicable diseases, a group of diseases that encompass a wide spectrum of pathologies, are particularly difficult to address even in a functioning health systems. Some of the problems may have been addressed, but with others falling by the wayside due to limited infrastructure and resources. During emergencies when health systems have been disrupted, even basic health needs may not be addressed and lead to an exacerbation of existing burdens. Inevitably, these diseases, traditionally not foreseen by humanitarian actors, contribute to significant levels of morbidity, disability and mortality.

The need to bridge together the humanitarian objectives and development objectives are integral in rebuilding health systems. However, the NCD kit was not intended to address the multiple disruptions health systems face at a time of an emergency. Under the framework of the health system's building blocks, the primary purpose of the kit was to respond to supply

Funding: None.

Competing interests: None declared chains disruption, providing a core set of essential medical supplies for the management of the most common NCD conditions. Focusing on the most common NCDs, the kit supports countries in providing continuity of care for people already treated for NCD conditions; thus, preventing acute exacerbations that would put an exponential burden on health systems.

By these means, it is expected that the kit not only improves the provision of essential services during acute emergency responses, but also paves the way for health system recovery. Therefore, it would anticipate the restoration of a regular $\mathrm{PHC}$ service delivery system with a focus on the most cost-effective NCD interventions, as recommended by WHO (22). By stockpiling medicines during, or even before emergencies, the kit can help countries mitigate disruptions in the future. Finally, from a funding perspective, in a climate when NCD care is on many donors' agendas, the kit can be an advocacy tool to prioritize the most cost-effective interventions and to orient donor funding for NCDs in humanitarian responses. 


\section{Élaboration d'un kit sanitaire d'urgence pour les maladies non transmissibles}

\section{Résumé}

Le kit sanitaire d'urgence pour les maladies non transmissibles (MNT) a été mis au point en réponse à l'augmentation de la prévalence des MNT dans les pays à revenu faible et intermédiaire. Dans les situations de conflit ou à la suite de catastrophes naturelles, les traitements réguliers pour cette catégorie de maladies sont souvent interrompus et la priorité leur est rarement donnée. Ceci conduit à une morbidité et une mortalité plus élevées, tant sur le court terme que sur le long terme. Non seulement la Région de la Méditerranée orientale affiche une incidence élevée pour les MNT, mais elle est aussi actuellement le lieu de plusieurs conflits de grande ampleur et accueille la plus importante population de réfugiés au monde. Pour cette raison, le Bureau régional de l'OMS pour la Méditerranée orientale a amorcé l'élaboration d'un kit sanitaire d'urgence pour les MNT afin de fournir un ensemble structuré de médicaments, de matériel et de fournitures renouvelables permettant de répondre aux besoins de 10000 personnes sur une période de trois mois après l'interruption des services médicaux normaux . Le présent rapport examine les raisons de l'élaboration d'un kit sanitaire d'urgence pour les MNT et la façon dont il pourra être utilisé, ainsi que les critères de sélection, sa structure, son contenu et ses processus de quantification. Enfin, les dernières étapes sont examinées, notamment l'achat, les aspects logistiques et les processus de suivi et d'évaluation du kit.

$$
\text { تصميم عدة المستلزمات الصحية الطارئة للأمر اض غير السارية }
$$

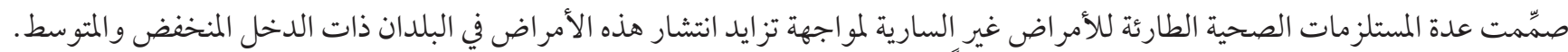

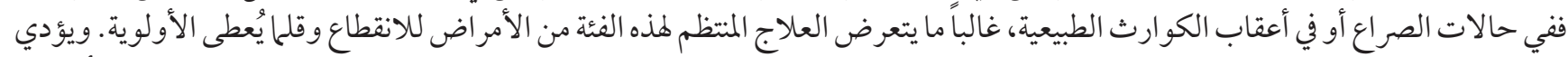

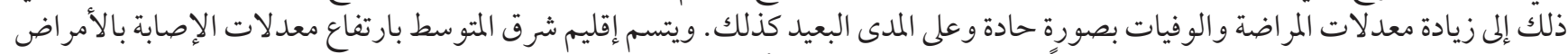

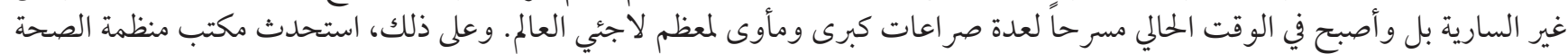

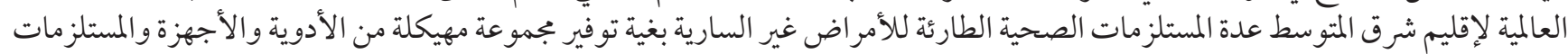

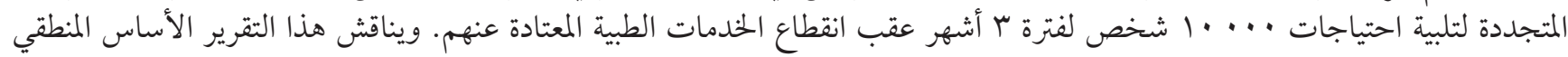

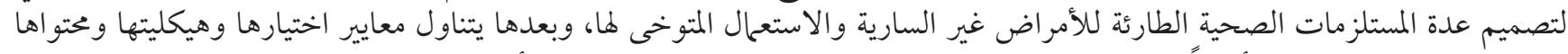

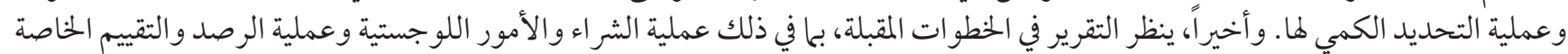
بمجمو عة المستلزمات.

\section{References}

1. World Health Organization. WHO emergency health kit: Standard drugs and clinic equipment for 10,00o persons for 3 months. Geneva: World Health Organization; 1984.

2. World Health Organization. The interagency emergency health kit 2011: Medicines and medical devices for 10,000 people for approximately three months. Geneva: Switzerland: World Health Organization; 2011.

3. World Health Organization. Standard health kits - Italian Emergency Kit A. Geneva: World Health Organization; 2016 (http:// www.who.int/hac/techguidance/ems/ems/en/).

4. United Nations Population Fund (UNFPA). Inter-agency reproductive health kits for crisis situations: Manual. New York: UNFPA; 2008.

5. Spiegel PB, Checchi F, Colombo S, Paik E. Health-care needs of people affected by conflict: future trends and changing frameworks. Lancet. 2010 Jan 23;375(9711):341-5. https://doi.org/10.1016/So140-6736(09)61873-0 PMID:20109961

6. World Health Organization. Global status report on noncommunicable diseases 2014. Geneva: World Health Organization; 2014.

7. World Health Organization. Global action plan for the prevention and control of noncommunicable diseases 2013-2020. Geneva: World Health Organization; 2013.

8. World Health Organization. Global health observatory data repository. Geneva: World Health Organization; 2017 (http://apps. who.int/gho/data/view.main.2464ESTSTANDARD?lang=en).

9. World Health Organization. Noncommunicable diseases country profiles 2014. Geneva: World Health Organization; 2017 (http:// www.who.int/nmh/countries/en/).

10. United Nations High Commissioner for Refugees (UNHCR). Global trends: forced displacement in 2015. Geneva: UNHCR; 2015 (https://s3.amazonaws.com/unhcrsharedmedia/2016/2016-06-20-global-trends/2016-06-14-Global-Trends-2015.pdf).

11. Internal Displacement Monitoring Centre (IDMC). Grid 2016: global report on Internal displacement. Geneva: IDMC; 2016 (http://www.internal-displacement.org/globalreport2016/). 
12. The Sphere Project. Essential health services - non-communicable diseases standard 1: non-communicable diseases. (http:// www.spherehandbook.org/en/essential-health-services-non-communicable-diseases-standard-1-non-communicable-diseases/).

13. World Health Organization. WHO model lists of essential medicines. Geneva: World Health Organization; 2015(http://www.who. int/medicines/publications/essentialmedicines/en/).

14. World Health Organization. Package of essential NCD interventions for primary health care: cancer, diabetes, heart disease and stroke, chronic respiratory disease. Geneva: World Health Organization; 2010 (http://www.who.int/cardiovascular_diseases/ publications/pen2010/en/).

15. World Health Organization. MhGAP intervention guide for mental, neurological and substance use disorders in nonspecialized health settings. Geneva: World Health Organization; 2010 (http://www.who.int/mental_health/publications/mhGAP_ intervention_guide/en/).

16. Word Health Organization. Management of noncommunicable diseases in conflict situations, with reference to the Syrian Arab Republic: a situation analysis. Unpublished review (2016).

17. World Health Organization. The selection and use of essential medicines: report of the WHO expert committee, 2013 (including the 18th WHO model list of essential medicines and the 4th WHO model list of essential medicines for children). Geneva: World Health Organization; 2013.

18. World Health Organization. Global Report on Diabetes. Geneva: World Health Organization; 2016.

19. World Health Organization. Tracking universal health coverage: first global monitoring report. Geneva: World Health Organization; 2015 .

20. Zhou B, Bentham J, Di Cesare M, Bixby H, Danaei G, Cowan MJ, et al.; NCD Risk Factor Collaboration (NCD-RisC). Worldwide trends in blood pressure from 1975 to 2015: a pooled analysis of 1479 population-based measurement studies with 19.1 million participants. Lancet. 201701 7;389(10064):37-55. https://doi.org/10.1016/So140-6736(16)31919-5 PMID:27863813

21. Kruk ME, Myers M, Varpilah ST, Dahn BT. What is a resilient health system? Lessons from Ebola. Lancet. 2015 May 9;385(9980):1910-2. https://doi.org/10.1016/So140-6736(15)60755-3 PMID:25987159

22. Martinez RE, Quintana R, Go JJ, Villones MS, Marquez MA. Use of the WHO package of essential noncommunicable diA sease interventions after Typhoon Haiyan. West Pac Surveill Response. 201511 6;6 Suppl 1:18-20. https://doi.org/10.5365/ wpsar.2015.6.3.HYN_024 PMID:26767129 